\title{
Comparative Spectroscopic Studies on Pure, 10 and 50 mol\% Glycine Mixed L-Valinium Picrate Crystals
}

\author{
Antony A. Joseph ${ }^{1}$, John David I. Ebenezar ${ }^{2}$, Ramachandra C. Raja ${ }^{3^{*}}$ \\ ${ }^{1}$ St. Joseph's College of Engineering \& Technology, Thanjavur, India \\ ${ }^{2}$ TBML College, Porayar, India \\ ${ }^{3}$ Government Arts College (Autonomous), Kumbakonam, India

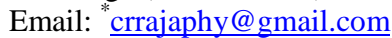

Received September 12, 2013; revised October 22, 2013; accepted November 3, 2013

Copyright (C) 2014 Antony A. Joseph et al. This is an open access article distributed under the Creative Commons Attribution License, which permits unrestricted use, distribution, and reproduction in any medium, provided the original work is properly cited. In accordance of the Creative Commons Attribution License all Copyrights (C) 2014 are reserved for SCIRP and the owner of the intellectual property Antony A. Joseph et al. All Copyright @ 2014 are guarded by law and by SCIRP as a guardian.

\begin{abstract}
Nonlinear optical crystals of pure, 10 and 50 mol\% glycine mixed L-valinium picrate have been grown from saturated aqueous solution by slow evaporation method at a temperature of $36^{\circ} \mathrm{C}$ using a constant temperature bath of accuracy of $\pm 0.01{ }^{\circ} \mathrm{C}$. The synthesized organic optical material has been purified by repeated recrystallization. The cell parameters were calculated using single crystal X-ray diffraction technique which confirmed the crystal system. Optical behavior was examined by UV-Vis-NIR spectrometer in the range from $190 \mathrm{~nm}$ to 1100 $\mathrm{nm}$, which revealed the absence of absorption in the entire visible region. Functional groups and modes of vibration were identified by FT-IR spectrometer in the range between $400 \mathrm{~cm}^{-1}$ and $4000 \mathrm{~cm}^{-1}$. The ${ }^{1} \mathrm{H}$ - and ${ }^{13} \mathrm{C}$ NMR spectra of grown crystals were recorded using $\mathrm{D}_{2} \mathrm{O}$ as solvent on a Bruker $300 \mathrm{MHz}$ (Ultrashield) TM instrument at $23^{\circ} \mathrm{C}\left(300 \mathrm{MHz}\right.$ for ${ }^{1} \mathrm{H}$ NMR and $75 \mathrm{MHz}$ for $\left.{ }^{13} \mathrm{C} \mathrm{NMR}\right)$ to confirm the molecular structure. The second harmonic generation conversion efficiency was investigated by Kurtz powder method using Nd: YAG laser as a source to explore the NLO characteristics.
\end{abstract}

\section{KEYWORDS}

\section{Crystal Growth; L-Valinium Picrate; FT-IR; Nuclear Magnetic Resonance; SHG; NLO}

\section{Introduction}

To satisfy the modern society's demand for photonics and telecommunication, extensive search of new nonlinear optical (NLO) materials is very essential [1]. The investigations on new nonlinear optical crystals with high second harmonic generation efficiency are more attractive because of their application in the field of telecommunication, optical computing and optical storage [2,3]. Organic nonlinear optical crystals are more resourceful materials for NLO applications compared to inorganic materials due to their large electro-optic coefficient with low frequency dispersion and high nonlinearity [4]. Due to chiral symmetry and noncentro symmetric properties, complex of amino acid with organic acid is promising materials for NLO applications [5]. Hence, lots of researches are being carried out to synthesize new organic *Corresponding author.
NLO materials. In our laboratory, we engaged in finding new NLO materials and some of the results were reported recently [6-8]. Growth and characterization on nonlinear optical crystal L-valinium picrate were carried out and reported earlier [9-12]. Growth and characterization on L-valinium picrate and $10 \mathrm{~mol} \%$ of glycine mixed L-valinium picrate were reported by other authors [13, 14]. In the present investigation, the synthesis and growth of pure, 10 and 50 mol\% glycine mixed L-valinium picrate crystals from its aqueous solution by slow evaporation have been reported. The cell parameters were calculated using single crystal X-ray diffraction studies. Using UV-Vis-NIR spectrum, transmission properties were reported. Functional groups were identified by FT-IR analysis. The chemical structure was discussed using FT-NMR technique and SHG test was also performed to confirm the NLO property. 


\section{Crystal Growth}

Analar grade samples of glycine, valine and picric acid were employed for the synthesis of L-valinium picrate (LVP). $10 \mathrm{~mol} \%$ glycine mixed L-valinium picrate (10 GVP) and 50 mol\% glycine mixed L-valinium picrate (50 GVP). LVP was synthesized by the reaction between picric acid and the amino acid, L-valine taken in equi-<smiles>CCCCCCCCCC(=O)O[N+](=O)c1cc([N+](=O)[O-])c(O)c([N+](=O)[O-])c1</smiles>

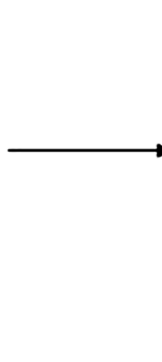

The purified powder of LVP, 10 GVP and 50 GVP were dissolved thoroughly in double distilled water at $30^{\circ} \mathrm{C}$ to form saturated solution. The solutions were heated to remove any undissolved substance and filtered to remove the dust particles. Then the solutions were kept aside undisturbed for the growth of single crystal. After two weeks, good quality transparent crystals were harvested.

\section{Result and Discussion}

\subsection{XRD Technique}

The single crystal diffraction analysis of LVP, 10 GVP and 50 GVP were carried out using ENRAF NONIUS CAD-4 single X-ray diffractometer with $\mathrm{MoK} \alpha(\lambda=$ $0.71073 \AA$ ) radiation. From the XRD data, it was observed that $10 \mathrm{GVP}$ crystallizes in orthorhombic crystal system and LVP, 50 GVP crystallizes in monoclinic system. The observed cell parameters are tabulated in the Table 1.

\subsection{UV-Vis-NIR Analysis}

The UV-Vis-NIR spectrum of grown crystals were recorded using Lambda 35 double beam spectrometer in the range at $190 \mathrm{~nm}$ to $1100 \mathrm{~nm}$ and it is shown in Figure 1. From the transmission spectrum, it was observed that the grown crystal has transparency from $425 \mathrm{~nm}$ to $1100 \mathrm{~nm}$. molar ratio. $10 \mathrm{GVP}$ has been grown from glycine, valine and picric acid taken in the ratio of 0.1:0.9:1 (Glycine: Valine: Picric Acid) in the deionized water. Same procedure was carried out to obtain 50 GVP in the ratio of 0.5:0.5:1 (Glycine: Valine: Picric Acid). The purity of the synthesized materials was increased by successive recrystallization. The chemical reaction involved in growth of L-valinium picrate may be written as follows.

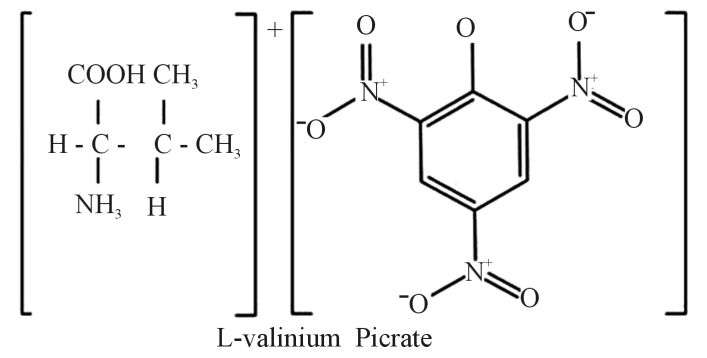

UV cut-off wavelength of L-valinium picrate (LVP), 10 mol\% glycine mixed L-valinium picrate (10 GVP) and 50 mol\% glycine mixed L-valinium picrate (50 GVP) are $425 \mathrm{~nm}, 460 \mathrm{~nm}$ and $450 \mathrm{~nm}$ respectively. The transparency above the $460 \mathrm{~nm}$ satisfies the requirement for frequency doubling of Nd: YAG laser. The observed peaks in the range between $200 \mathrm{~nm}$ to $360 \mathrm{~nm}$, were due to transition from $n$ to $\Pi^{*}$ transitions of carbonyl group [15].

\subsection{FT-IR Analysis}

The FT-IR spectrum of grown crystals were recorded in the $\mathrm{KBr}$ phase in the frequency region of $400-4000$ $\mathrm{cm}^{-1}$ using Perkin-Elmer FT-IR spectrometer (model SPECTRUMRX1) and shown in Figure 2. The recorded spectrum was compared with the available literature [16]. The observed vibrational frequencies and their tentative assignments are given in the Table 2.

The stretching vibration of $\mathrm{NH}_{3}^{+}$of amino acid was observed at 3088, 3080 and $3081 \mathrm{~cm}^{-1}$ in LVP, 10 GVP, 50 GVP respectively which was found due to superimposed of $\mathrm{OH}$ and $\mathrm{NH}_{3}^{+}$stretching bands. A broad absorption occurred around $3446 \mathrm{~cm}^{-1}$ (LVP) $3428 \mathrm{~cm}^{-1}$ (10 GVP), $3432 \mathrm{~cm}^{-1}$ (50 GVP) due to $\mathrm{OH}$ stretching band. The absorptions around $1720 \mathrm{~cm}^{-1}$ and $1480 \mathrm{~cm}^{-1}$ of all the three spectrums are due to stretching of $\mathrm{COO}^{-}$ bands. The rocking vibration of $\mathrm{NH}_{3}$ and $\mathrm{CH}_{2}$ was

Table 1. Lattice parameter values of grown crystals.

\begin{tabular}{|c|c|c|c|c|c|c|c|c|}
\hline Sample & $\mathbf{a}\left(\mathbf{A}^{\circ}\right)$ & $\mathbf{b}\left(\mathbf{A}^{\circ}\right)$ & $\mathbf{c}\left(\mathbf{A}^{\circ}\right)$ & $\alpha$ (degree) & $\beta$ (degree) & $\gamma$ (degree) & Volume $A^{\circ 3}$ & Crystal System \\
\hline LVP & 9.97 & 6.29 & 12.64 & 90 & 110 & 90 & 793 & Monoclinic \\
\hline $10 \mathrm{GVP}$ & 9.22 & 9.69 & 19.06 & 90 & 90 & 90 & 1702 & Orthorhombic \\
\hline 50 GVP & 10.01 & 6.31 & 12.67 & 90 & 110 & 90 & 800 & Monoclinic \\
\hline
\end{tabular}




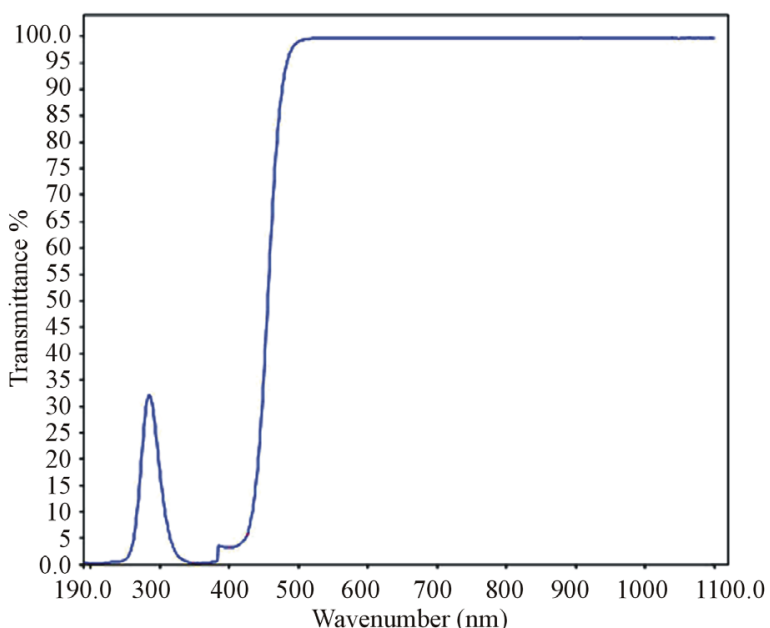

(a)

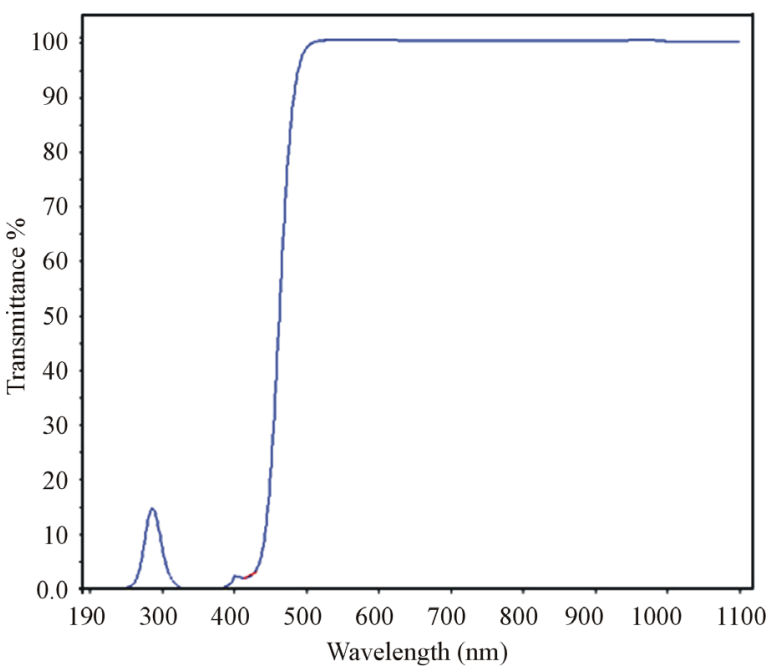

(b)

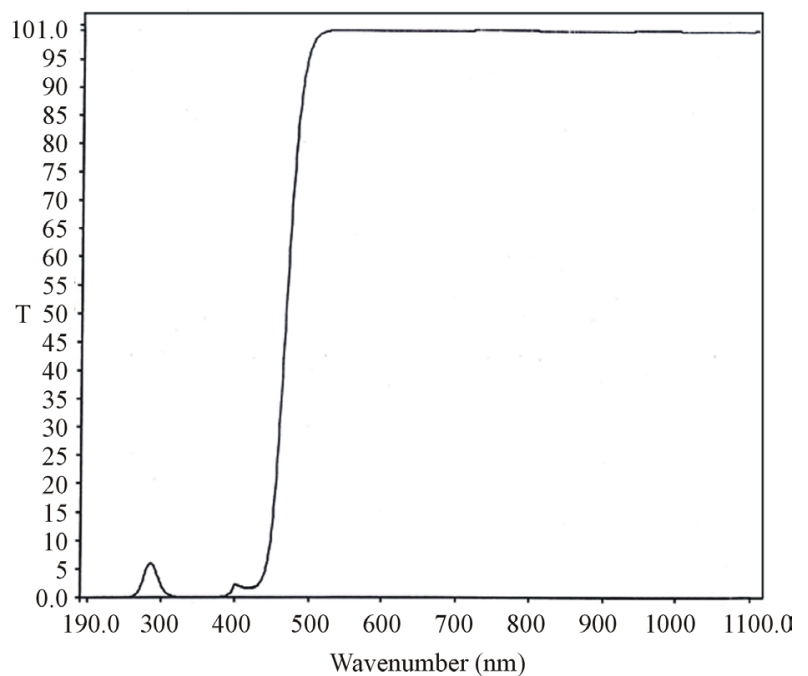

(c)

Figure 1. (a) Transmission spectrum of LVP; (b) Transmission spectrum of 10 GVP; (c) Transmission spectrum of 50 GVP.

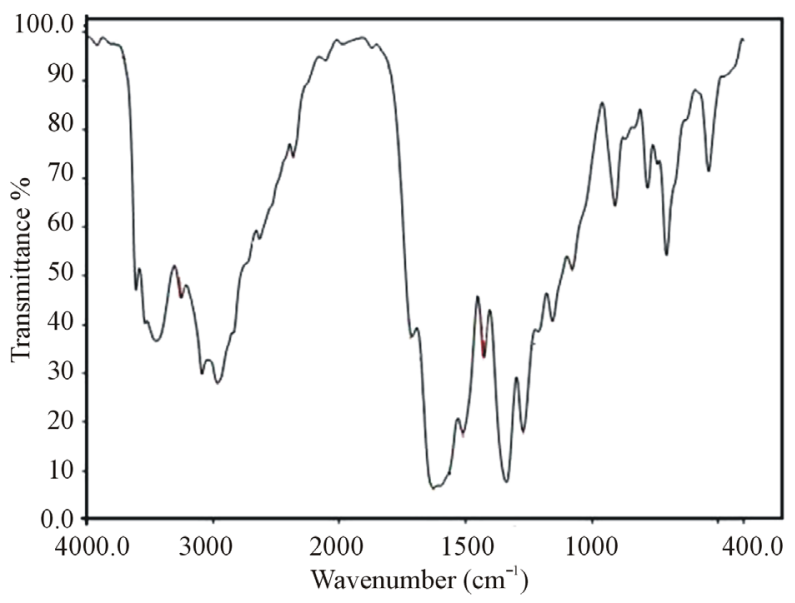

(a)

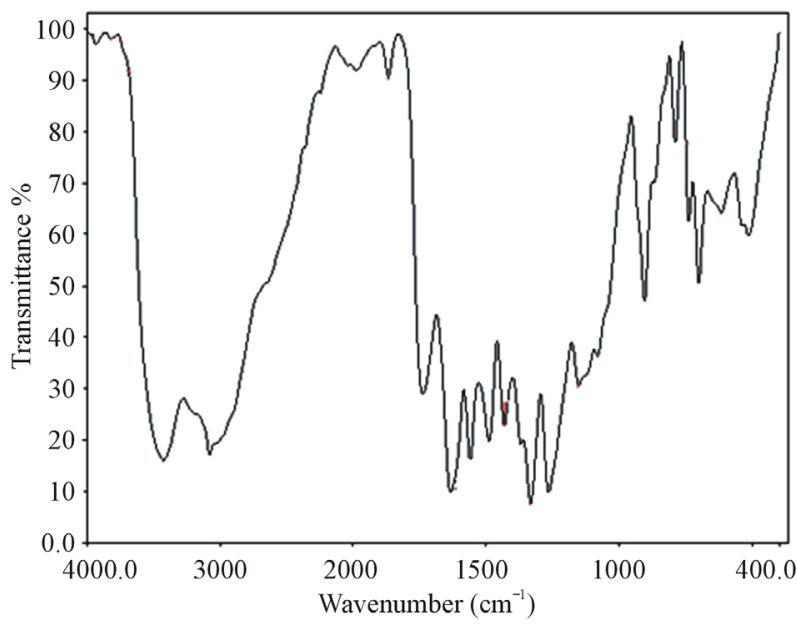

(b)

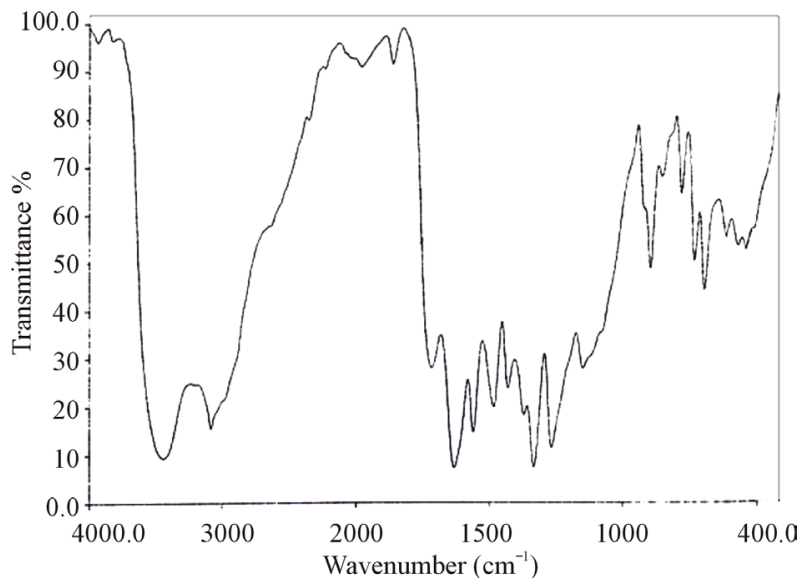

(c)

Figure 2. (a) FT-IR spectrum of LVP; (b) FT-IR spectrum of $10 \mathrm{GVP}$; (c) FT-IR spectrum of 50 GVP.

observed around $1153 \mathrm{~cm}^{-1}$ and $906 \mathrm{~cm}^{-1}$ in all the cases. The incorporation of glycine in L-valinium picrate is confirmed by presence of peak at $618 \mathrm{~cm}^{-1}$ in $10 \mathrm{GVP}$ and $620 \mathrm{~cm}^{-1}$ in $50 \mathrm{GVP}$ and it is obtained due to stretching 
Table 2. FT-IR Spectral data.

\begin{tabular}{|c|c|c|c|}
\hline \multicolumn{3}{|c|}{ Observed frequency in $\mathrm{cm}^{-1}$} & \multirow{2}{*}{ Assignments } \\
\hline LVP [14] & 10 GVP & 50 GVP & \\
\hline 3446 & 3428 & 3432 & OH stretching \\
\hline 3088 & 3080 & 3081 & $\mathrm{NH}_{3}^{+}$asymmetric stretching \\
\hline 1716 & 1739 & 1720 & $\mathrm{COO}^{-}$symmetric stretching \\
\hline 1633 & 1633 & 1633 & $\mathrm{NH}_{3}^{+}$asymmetric symmetric \\
\hline 1565 & 1561 & 1561 & $\mathrm{NH}_{3}^{+} \quad$ symmetric stretching \\
\hline 1465 & 1489 & 1486 & $\mathrm{CH}_{3}$ asymmetric stretching \\
\hline 1427 & 1433 & 1433 & $\mathrm{COO}^{-}$symmetric stretching \\
\hline 1337 & 1333 & 1334 & $\mathrm{NO}_{2}$ symmetric stretching \\
\hline 1274 & 1266 & 1268 & $\mathrm{C}-\mathrm{COO}^{-}$stretching \\
\hline 1157 & 1153 & 1153 & $\mathrm{NH}_{3}^{+}$rocking \\
\hline 1079 & 1082 & 1080 & C-N stretching \\
\hline 906 & 906 & 905 & $\mathrm{CH}_{2}$ rocking \\
\hline 784 & 740 & 742 & $\mathrm{NO}_{2}$ bending \\
\hline- & 618 & 620 & $\mathrm{C}=\mathrm{O}$ stretching of glycine \\
\hline 540 & 516 & 546 & $\mathrm{COO}^{-}$rocking \\
\hline
\end{tabular}

of $\mathrm{C}=\mathrm{O}$ group of glycine. The absorptions of $10 \mathrm{GVP}$ and 50 GVP have been compared with those of parent compound (LVP) and its shows shifts in the position of characteristics peak which confirm the formation of the new compound.

\subsection{NMR Studies}

The ${ }^{1} \mathrm{H}-\mathrm{NMR}$ and ${ }^{13} \mathrm{C}-\mathrm{NMR}$ spectra of LVP, 10 GVP and 50 GVP crystals were recorded using $\mathrm{D}_{2} \mathrm{O}$ as solvent on a Bruker FT-NMR spectrometer. The spectra were recorded by dissolving the sample in $\mathrm{D}_{2} \mathrm{O}$ and obtained spectra are shown in the Figures 3 and 4. The chemical shifts for ${ }^{1} \mathrm{H}-\mathrm{NMR}$ and ${ }^{13} \mathrm{C}-\mathrm{NMR}$ spectrums are represented in $\delta \mathrm{ppm}$ and are tabulated in the Table 3.

The proton in the glycine and picric acid was assigned with the help of the available literature $[17,18]$. In ${ }^{1} \mathrm{H}-$ NMRspectrum, the OH-proton of picric acid pf LVP, 10 GVP and 50 GVP are observed at $\delta=8.75$, 8.54 and 8.73 ppm respectively. The same was observed at $\delta=11.94$ ppm in free picric acid $[18,19]$. This upfield shift was due to the shielding of $\mathrm{OH}$ proton by the $\Omega$ and $n$ electron of glycine, confirming the charge transfer phenomenon in the compound [20]. The sharp and intense peak at $\delta=$ $4.8 \mathrm{ppm}$ was due to the presence of undeuteriated $\mathrm{D}_{2} \mathrm{O}$ as solvent. The resonance signal observed around $\delta=3.79$ ppm of LVP, $\delta=3.75 \mathrm{ppm}$ of $10 \mathrm{GVP}$ and $\delta=3.75 \mathrm{ppm}$ of $50 \mathrm{GVP}$ are attributed to $\mathrm{CH}$ proton of L-valine next

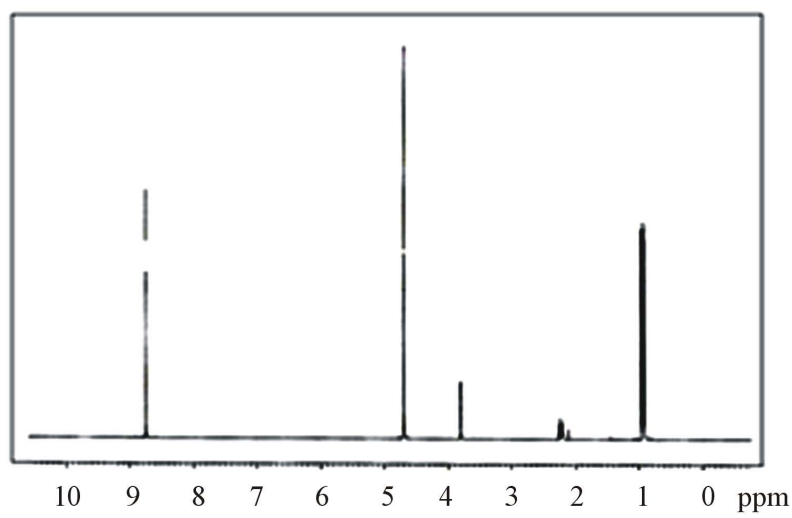

(a)

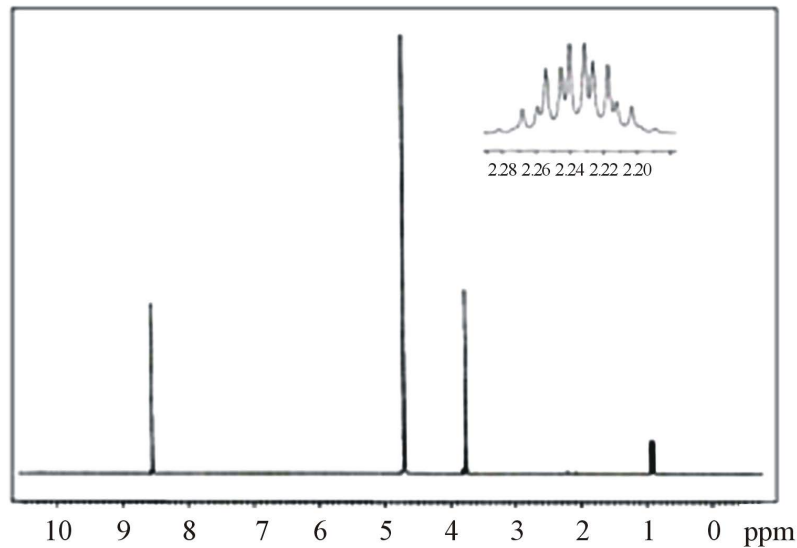

(b)

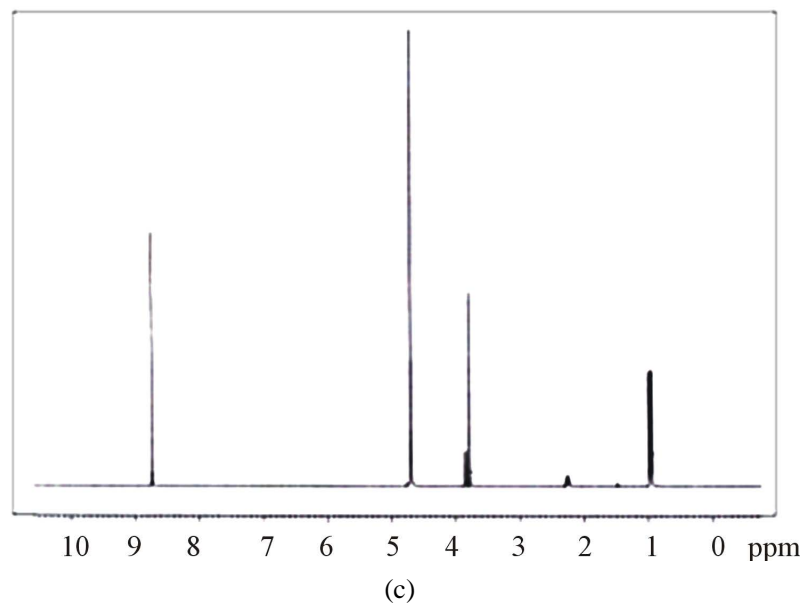

Figure 3. (a) ${ }^{1} \mathrm{H}-\mathrm{NMR}$ spectrum of LVP; (b) ${ }^{1} \mathrm{H}$-NMR spectrum of 10 GVP crystal; (c) ${ }^{1} \mathrm{H}$-NMR spectrum of 50 GVP crystal.

to carboxylic acid [21]. The doublets observed around at $\delta=0.8 \mathrm{ppm}$ to $0.9 \mathrm{ppm}$ are assigned to the proton of two $\mathrm{CH}_{3}$ group of L-valine in all three crystals. The signal observed at $\delta=3.85$ and $3.83 \mathrm{ppm}$ of $10 \mathrm{GVP}$ and 50 GVP respectively are due to the protons present in the $\left(\mathrm{CH}_{2}\right)$ group of glycine which indicates that addition of glycine in L-valinium picrate. 


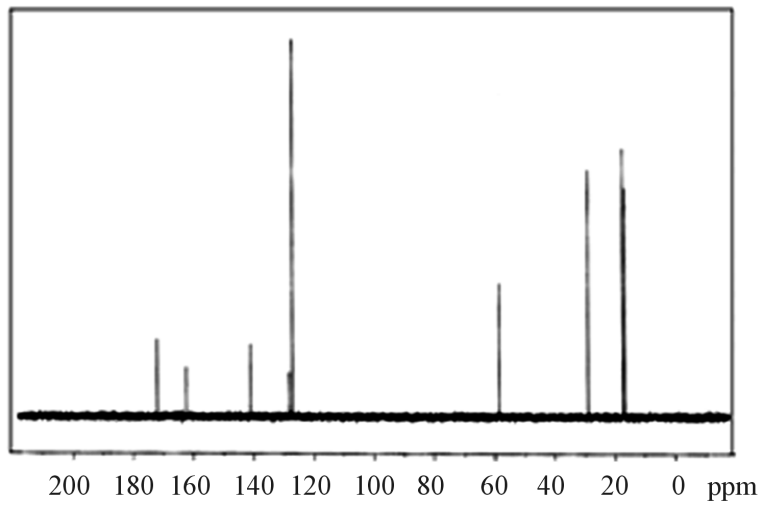

(a)

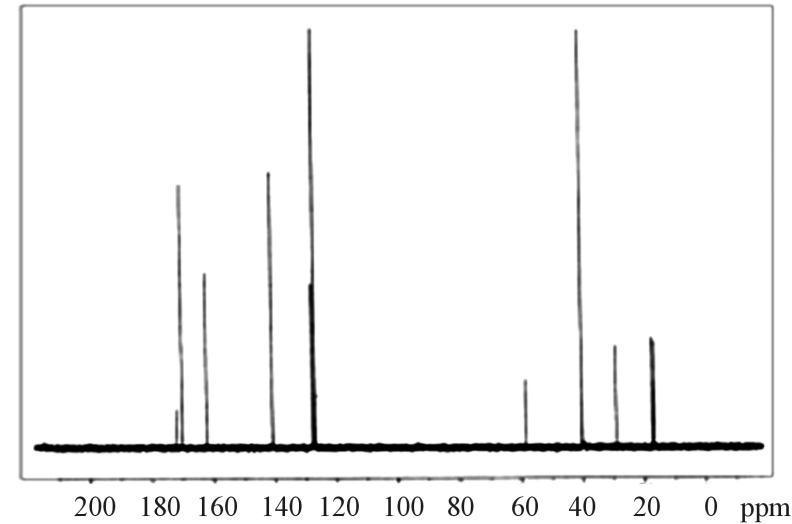

(b)

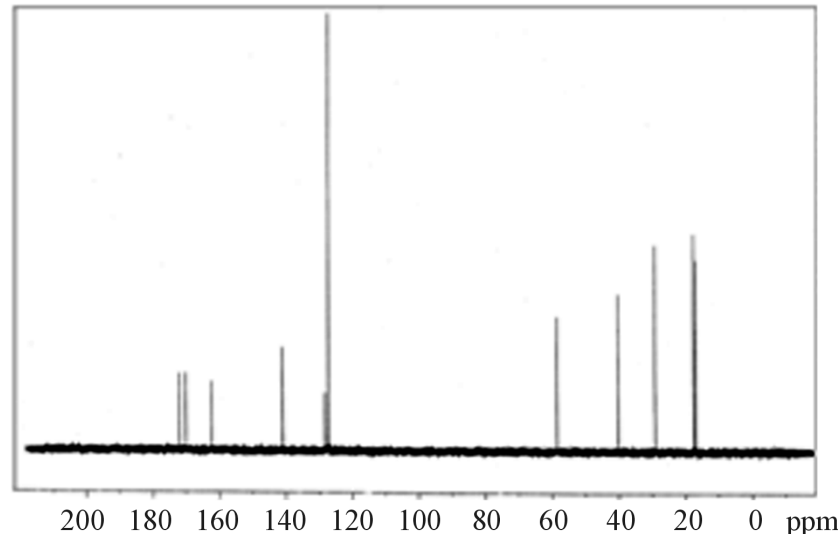

(c)

Figure 4. (a) ${ }^{13} \mathrm{C}-\mathrm{NMR}$ spectrum of LVP; (b) ${ }^{13} \mathrm{C}-\mathrm{NMR}$ spectrum of $10 \mathrm{GVP}$ crystal; (c) ${ }^{13} \mathrm{C}-\mathrm{NMR}$ spectrum of $50 \mathrm{GVP}$ crystal.

Table $3 .{ }^{1} \mathbf{H}$ and ${ }^{13} \mathrm{C}$-NMR chemical shift values of LVP.

\begin{tabular}{|c|c|c|c|c|}
\hline \multirow{2}{*}{ Spectra } & \multicolumn{3}{|c|}{ Chemical Shift ( $\delta$ ppm) } & \multirow{2}{*}{ Group identification } \\
\hline & LVP & 10 GVP & 50 GVP & \\
\hline \multirow{5}{*}{${ }^{1} \mathrm{H}-\mathrm{NMR}$} & $0.8 \& 0.9$ & $0.89 \& 0.93$ & $0.93 \& 0.97$ & $-\mathrm{CH}_{3}$ —of L-valine \\
\hline & 3.79 & 3.75 & 3.78 & -CH—of L-valine \\
\hline & - & 3.85 & 3.83 & $-\mathrm{CH}_{2}$ - of glycine \\
\hline & 4.8 & 4.8 & 4.8 & $\mathrm{D}_{2} \mathrm{O}$ \\
\hline & 8.75 & 8.54 & 8.73 & OH-proton of Picric Acid \\
\hline \multirow{10}{*}{${ }^{13} \mathrm{C}-\mathrm{NMR}$} & $16.75 \& 17.41$ & $16.77 \& 17.35$ & $16.78 \& 17.39$ & $-\mathrm{CH}_{3}$ - of L-valine \\
\hline & 29.03 & 29.03 & 29.04 & -CH—of L-valine \\
\hline & - & 40.14 & 40.14 & $-\mathrm{CH}_{2}$ - of glycine \\
\hline & 58.64 & 58.51 & 58.55 & -CH—of L-valine \\
\hline & 128.26 & 127.80 & 128.22 & $\mathrm{C}_{4}$ carbon atom of Picric Acid \\
\hline & 127.21 & 127.01 & 127.19 & $\mathrm{C}_{3}$ and $\mathrm{C}_{5}$ carbon atoms of Picric Acid \\
\hline & 141.12 & 140.81 & 141.04 & $\mathrm{C}_{2}$ and $\mathrm{C}_{6}$ carbon atoms of Picric Acid \\
\hline & 162.38 & 162.17 & 162.30 & Ipso carbon of Picric Acid \\
\hline & 172.01 & 170.08 & 170.08 & $\mathrm{COOH}$ of L-valine \\
\hline & - & 171.85 & 171.89 & $\mathrm{COOH}$ of glycine \\
\hline
\end{tabular}


In ${ }^{13} \mathrm{C}$-NMR spectrum, the signals observed at $\delta=$ 172.01, 170.08 and $170.08 \mathrm{ppm}$ of LVP, $10 \mathrm{GVP}$ and 50 GVP were due to presence of $\mathrm{COOH}$ of L-valine. The characteristic peak nearly at $\delta=162 \mathrm{ppm}$ of three crystals were attributed to ipso carbon of picric acid. The observed peak arround $\delta=141 \mathrm{ppm}$ of three crystals were due to $\mathrm{C}_{2}$ and $\mathrm{C}_{6}$ carbon atom containing $\mathrm{NO}_{2}$ group in picric acid molecule. The signals at $\delta=128.26,127.80$ and $128.22 \mathrm{ppm}$ of grown crystals are assigned to $\mathrm{C}_{4}$ carbon atom of picric acid. The peaks at $\delta=127.21,127.01$ and $127.19 \mathrm{ppm}$ are assigned to $\mathrm{C}_{3}$ and $\mathrm{C}_{5}$ carbon of picric acid of LVP, 10 GVP and 50 GVP respectively. The resonance signal was observed at $\delta=58.64,58.51$ and 58.55 are due to tertiary carbon connected to L-valine. The signal around $\delta=29.03 \mathrm{ppm}$ represents the $\mathrm{CH}$ (isopropyl) groups of L-valine. The $\mathrm{CH}_{3}$ carbons of L-valine are observed nearly between 16 and $17 \mathrm{ppm}$. The resonance signals at $\delta=40.14 \mathrm{ppm}$ of $10 \mathrm{GVP}$ and $50 \mathrm{GVP}$ are account for the carbon of the $\mathrm{CH}_{2}$ group in glycine. The peaks at $\delta=171.85$ and 171.89 ppm of 10 GVP and 50 GVP respectively can be safely attributed to carboxyl group $(\mathrm{COOH})$ of glycine.

\subsection{SHG Test}

The nonlinear optical susceptibility of grown crystals were measured through second harmonic generation test using standard Kurtz and Perry Method [22]. The powdered sample is placed in the path of Nd: YAG laser with pulse width of $8 \mathrm{~ns}$ and repetition rate $10 \mathrm{~Hz}$. The intensity of incident power is $2.8 \mathrm{~mJ} /$ pulse for LVP, $50 \mathrm{GVP}$ crystals and $3.5 \mathrm{~mJ} /$ pulse for $10 \mathrm{GVP}$ crystals. The green color output signal from the sample confirmed the second harmonic generation. The intensity of output light was observed as $1300 \mathrm{mV}, 425 \mathrm{mV}$ and $1050 \mathrm{mV}$ for LVP, 10 GVP and 50 GVP crystals respectively.

\section{Conclusion}

Organic NLO material, L-valinium picrate (LVP), 10 mol\% glycine mixed L-valinium picrate (10 GVP) and 50 mol\% glycine mixed L-valinium picrate (50 GVP) were grown from aqueous solution in room temperature using slow evaporation technique. The cell parameters were determined by XRD analysis and crystal systems were found. The chemical environment of carbon and hydrogen in grown crystals was identified by FT-NMR technique and it confirmed the presence of dopent in parent crystals. The NLO effect was confirmed by Kurtz and Perry technique.

\section{Acknowledgements}

The authors acknowledge the help rendered by St. Joseph's College, Trichy, India, and SASTRA University, Thanjavur, India for spectral facilities. The correspond- ing authors are thankful to Central Electro Chemical Research Institute, Karaikudi, India for providing the thermal studies. The authors are grateful to Maduari Kamaraj University, Madurai for XRD studies.

\section{REFERENCES}

[1] D. J. Willams, "Organic Polymeric and Non-Polymeric Materials with Large Optical Nonlinearities,” Angewandte Chemie International Edition in English, Vol. 23, No. 9, 1984, pp. 690-703. http://dx.doi.org/10.1002/anie.198406901

[2] V. G. Dmitriev, G. G. Gurzadyan, D. N. Nicogosyan, et al., "Hand Book of Nonlinear Optical Crystals," SpringerVerlag, New York, 1999. http://dx.doi.org/10.1007/978-3-540-46793-9

[3] P. N. Prasad and D. J. Williams, "Introduction to Nonlinear Optical Effect in Molecules and Polymers,” John Wiley \& Sons Inc., Hoboken, 1991.

[4] D. S. Chemla and J. Zyss, "Nonlinear Optical Properties of Organic Molecules and Crystals," Academic Press, New York, 1987.

[5] M. N. Bhat and S. M. Dharmaprakash, "New Nonlinear Optical Material: Glycine Sodium Nitrate," Journal of Crystal Growth, Vol. 235, No. 1-4, 2002, pp. 511-516. http://dx.doi.org/10.1016/S0022-0248(01)01799-7

[6] C. R. Raja and A. A. Joseph, "Crystal Growth and Characterization of New Nonlinear Optical Single Crystals of L-Alaninium Fumarate,” Materials Letters, Vol. 63, No. 28, 2009, pp. 2507-2509. http://dx.doi.org/10.1016/j.matlet.2009.08.046

[7] C. R. Raja and A. A. Joseph, "Crystal Growth and Comparative Studies of XRD, Spectral Studies on New NLO Crystals: L-Valine and L-Valinium Succinate,” Spectrochima Acta A, Vol. 74, No. 3, 2009, pp. 825-828. http://dx.doi.org/10.1016/j.saa.2009.08.023

[8] C. R. Raja, G. Gokila and A. A. Joseph, "Growth and Spectroscopic Characterization of a New Organic Nonlinear Optical Crystal: L-Alaninium Succinate,” Spectrochima Acta A, Vol. 72, No. 4, 2009, pp. 753-756. http://dx.doi.org/10.1016/j.saa.2008.11.030

[9] S. A. Martin Britto Dhas and S. Natarajan, "Growth and Characterization of a New Potential Second Harmonic Generation Material from the Amino Acid Family: L-Valinium Picrate," Crystal Research and Technology, Vol. 43, No. 8, 2008, pp. 869-873. http://dx.doi.org/10.1002/crat.200711152

[10] P. Srinivasan, T. Kanagasekaran and R. Gopalakrishnan, "A Highly Efficient Organic Nonlinear Optical DonorAcceptor Single Crystal: l-Valinium Picrate,” Crystal Growth \& Design, Vol. 8, No. 7, 2008, pp. 2340-2345. http://dx.doi.org/10.1021/cg701143n

[11] S. Senthilkumar, M. B. Mary and V. Ramakrishnan, "Infrared and Raman Spectroscopic Studies of L-Valinium Picrate,” Journal of Raman Spectroscopy, Vol. 38, No. 3, 2007, pp. 288-294. http://dx.doi.org/10.1002/jrs.1641

[12] K. Anitha, B. Sridhar and K. K. Rajaram, "L-Valinium Picrate,” Acta Cryst., Vol. E60, 2004, pp. o1530-o1532. 
http://dx.doi.org/10.1107/S160053680401949X

[13] A. A. Joseph, I. J. D. Ebenezar and C. R. Raja, "Crystal Growth, Spectral and NMR Studies of Nonlinear Optical Crystal: L-Valinium Picrate,” Optik-International Journal for Light and Electron Optics, Vol. 123, No. 16, 2012, pp. 1436-1439.

http://dx.doi.org/10.1016/j.ijleo.2011.07.064

[14] A. A. Joseph, I. J. D. Ebenezar and C. R. Raja, "Spectroscopic Studies on the Influence of $10 \mathrm{~mol} \%$ of Glycine on Nonlinear Optical Crystal l-Valinium Picrate," Spectrochima Acta A, Vol. 82, No. 1, 2011, pp. 410-413. http://dx.doi.org/10.1016/j.saa.2011.07.071

[15] R. Mahalakshmi, S. X. Jesuraja and S. Jerome Das, "Growth and Characterization of L-Phenylalanine," Crystal Research and Technology, Vol. 41, No. 8, 2006, pp. 780-783. http://dx.doi.org/10.1002/crat.200510668

[16] K. Kirubavathi, K. Selvaraju, N. Vijayan and S. Kumararaman, "Synthesis Growth and Characterization of L-Valinium Picrate a New Nonlinear Optical Crystal," Spectrochimica Acta A, Vol. 71, No. 1, 2008, pp. 288-291. http://dx.doi.org/10.1016/j.saa.2008.02.028

[17] A. Chandramohan, R. Bharathikannan, M. A. Kandasawamy, J. Chandrasekaran and V. Kandavelu, "Synthesis, Crystal Growth, Spectral, Thermal and Optical Properties of Acenaphthene Picrate," Crystal Research and Technology, Vol. 43, No. 1, 2007, pp. 93-98. http://dx.doi.org/10.1002/crat.200710949

[18] R. Bharathikannan, A. Chandramohan, M. A. Kandasawamy, J. Chandrasekaran, R. Renganathan and V. Kandavelu, "Synthesis, Crystal Growth and Properties of the Charge Transfer Complex Adduct of 2-Nitro Aniline with Picric Acid-An Organic Non-Linear Optical Material," Crystal Research and Technology, Vol. 43, No. 6, 2008, pp. 683-688. http://dx.doi.org/10.1002/crat.200711114

[19] S. M. Teleb and A. S. Gaballa, "Preparation and Spectroscopic Studies on Charge-Transfer Complexes of 2,2'Bipyridine with Picric and Chloranilic Acids," Spectrochimica Acta A, Vol. 62, No. 1-3, 2005, pp. 140-145. http://dx.doi.org/10.1016/j.saa.2004.12.017

[20] V. R. Dani, “Organic Spectroscopy,” Tata Mcgraw-Hill, New Delhi, 1995.

[21] P. Y. Brice, “Organic Chemistry,” Pearson Edition (Singapore), New Delhi, 2002.

[22] S. K. Kurtz and T. T. Perry, "A Powder Technique for the Evaluation of Nonlinear Optical Materials," Journal of Applied Physics, Vol. 39, No. 8, 1968, p. 3798. http://dx.doi.org/10.1063/1.1656857 